\title{
A agroindústria familiar e práticas cotidianas: uma análise sob a ótica da teoria da atividade
}

O estudo do cotidiano se insere no campo acadêmico, como forma de conhecer a dinâmica presente no interior dos grupos. Assim sendo, objetivou-se com esse estudo analisar a estrutura básica das atividades desenvolvidas pelos membros de uma padaria artesanal, em suas atividades cotidianas, considerando as arenas e cenários relativos à reprodução social. Os procedimentos metodológicos utilizados foram a entrevista, observação direta e aplicação da Teoria da Atividade para avaliação das atividades desenvolvidas pelos sujeitos. Os resultados apontaram que as atividades realizadas pelo grupo são, em sua maioria, conjuntas, uma vez que trabalham em regime de cooperação, mesmo existindo atividades que são distintas entre os membros, além de cargos explícitos e implícitos que se estabeleceram devido às habilidades dos sujeitos e ao poder delegado a eles pelos demais membros do grupo.

Palavras-chave: Estudo do cotidiano; Teoria da atividade; Cooperação.

\section{The family agroindustry and everyday practices: an analysis under the optical theory of activity}

\begin{abstract}
The study of the daily one if it inserts in the academic field, as form of if knowing the present dynamics in the interior of the groups; thus being, it was objectified with this study to analyze the basic structure of the activities developed for the members of an artisan bakery, in its daily activities, considering the relative enclosures for bullfighting and scenes to the social reproduction. The used methodological procedures had been, the interview, direct comment and application of the Theory of the Activity for evaluation of the activities developed for the citizens. The results had pointed that the activities carried through for the group are carried through, in its majority, jointly, a time that work in regimen of the cooperation, even so exist activities that are distinct between the members; beyond explicit and implicit positions that if had established due to the abilities of the citizens and the delegated power they for the too much members of the group.
\end{abstract}

Keywords: Study of the daily one; Theory of the Activity; Cooperation.

\section{Topic: Terceiro Setor e Cooperativismo}

Reviewed anonymously in the process of blind peer.
Received: 29/01/2017

Approved: 31/03/2017
Virginia Arlinda da Silva Cardoso Universidade Federal de Ouro Preto, Brasil http://lattes.cnpq.br/2820374050218723 viviecd@yahoo.com.br

Alaércio de Sousa Cardoso

Universidade Federal de Viçosa, Brasil

http://lattes.cnpq.br/2553486111476797

alaesca@yahoo.com.br

Maria das Dores Saraiva de Loreto

Universidade Federal de Viçosa, Brasil

http://lattes.cnpq.br/6833406073308098

mdora@ufv.br
Amélia Carla Sobrinho Bifano

Universidade Federal de Viçosa, Brasil

http://lattes.cnpq.br/6205029941313302

abifano@ufv.br
Referencing this:

CARDOSO, V. A. S.; CARDOSO, A. S.; LORETO, M. D. S.; BIFANO, A. C. S. $A$ agroindústria familiar e práticas cotidianas: uma análise sob a ótica da teoria da atividade. Revista Brasileira de Administração Científica, v.8, n.1, p.343-356, 2017. DOI: http://doi.org/10.6008/SPC2179$684 X .2017 .001 .0025$ 


\section{INTRODUÇÃO}

O estudo do cotidiano, ainda que de maneira modesta, vem se inserindo no campo acadêmico, como alternativa aos estudos realizados em nível macro, em que são priorizadas as estruturas sociais, em detrimento da dinâmica presente no interior dos grupos, nas interrelações entre sujeitos, de onde surgem as mais variadas e férteis manifestações de necessidades, desejos e realizações dos indivíduos.

Embora essa temática apresente ambiguidades em termos de sua definição e compreensão, dependendo da vertente teórica em que se baseie, o mundo cotidiano, nesse estudo, é compreendido como uma maneira versátil e complexa de pensar e viver a realidade dos indivíduos, em que a realização das atividades se dá de maneira consciente e dinâmica no interior dos grupos, sejam eles famílias e ou comunidades, recolocando-se, desse modo, o sujeito no centro das discussões (LIMA, 1983; PENIN, 1989; LEFEBVRE, 1991; LAVE, 1991; LIMA, 1996; CERTEAU, 2000; MARASCHIN et al., 2002; BIFANO, 1999, 2007; GIL, 2008).

O cotidiano é percebido como repleto de improvisações complexas, em que os sujeitos agem de forma aparentemente similar, embora a atividade cotidiana seja sempre o produto e a reflexão de relações múltiplas, arraigadas aos valores e crenças, da interação entre as pessoas e das condições de produção e reprodução de suas atividades no tempo (BIFANO, 1999).

Desse modo, a atividade cotidiana se constitui no decorrer dos processos de interação, se desenvolvendo em um dado momento sócio histórico e cultural e em uma determinada situação. Os sujeitos, embora vivam em uma sociedade onde há uma pré-organização básica das atividades humanas, são autônomos na determinação das melhores maneiras de gerir tais atividades em seu cotidiano.

Para que haja essa autonomia na realização das atividades, é necessário que se conceba a existência de uma unidade e uma inseparabilidade entre a consciência humana e a realização de qualquer atividade. Com isso, reforça-se a ideia de que as atividades cotidianas não são meras repetições de ações, e sim um intrincado jogo simbólico, em que a mente humana trabalha incansavelmente para alcançar os objetivos propostos no dia a dia dos sujeitos.

Entendendo-se que o cotidiano é complexo e que se constitui por processos de ação e decisão dos sujeitos envolvidos, é possível pressupor que as formas pelas quais os sujeitos se organizam em prol de um objetivo comum, como a criação e a manutenção de um empreendimento agroindustrial na realidade concreta dos grupos integrantes, bem como estes a incorporam de acordo com suas convicções e valores, também é algo complexo. Para entendê-lo, é necessária a compreensão do contexto espaço-temporal da realidade cotidiana desse grupo, situando-o, tanto geográfica quanto socialmente, além de selecionar as arenas e acompanhar os cenários em que se dão essas interações. Assim sendo, o presente estudo objetivou identificar a estrutura básica das atividades cotidianas na padaria artesanal 'Mãos de Fibra', considerando as trocas ocorridas entre os envolvidos. 


\section{REVISÃO TEÓRICA}

\section{Teoria da Atividade}

A atividade é categoria central no materialismo histórico-dialético, e Marx (1989), ainda em seus primeiros escritos, aponta a atividade prática sensorial como o que dá origem ao desenvolvimento histórico social dos homens, e assim, também ao desenvolvimento individual. Partindo desse pressuposto básico do materialismo histórico-dialético, os psicólogos soviéticos elegem o conceito de atividade como um dos princípios centrais ao estudo do desenvolvimento do psiquismo.

Vygotsky utiliza o conceito de atividade já em seus primeiros escritos e sugere que a atividade socialmente significativa é o princípio explicativo da consciência, ou seja, a consciência é construída de fora para dentro por meio das relações sociais (KOZULIN, 2002). Consciência e atividade são, assim, dois elementos fundamentais à psicologia histórico-cultural e devem ser entendidos como unidade dialética.

Foi Leontiev quem sistematizou o conceito de atividade, fundando a teoria psicológica geral da atividade. Esse conceito desempenha as funções de princípio explicativo dos processos psicológicos superiores e de objeto de investigação. Assim, a teoria da atividade é um termo genérico para uma linha de teorias e pesquisas de ciências sociais ecléticas. Segundo Engestrom et al. (1999), tal teoria tem suas origens na filosofia alemã clássica soviética de Vygotsky, Leontiev e Luria, sendo muito difundida, principalmente a partir da década de 80, quando ganha repercussão mundial. Kuutti (1996), acrescenta que essa teoria atua como um suporte filosófico e multidisciplinar para estudar as diferentes formas das práticas humanas como processos de desenvolvimento, com os níveis social e individual interligados ao mesmo tempo.

Os estudiosos da teoria da atividade procuraram compreender as atividades humanas como fenômenos complexos e socialmente situados e ir além dos paradigmas da reflexologia (o ensino de Vladimir Bekhterev e seus seguidores) e da fisiologia da atividade nervosa superior (o ensino de Ivan Pavlov e sua escola), a psicanálise e o behaviorismo. A Teoria da Atividade surge então como corrente teórica que propõe um modelo que ilustrasse que o comportamento humano, diferente dos outros animais, é indireto, mediado. Neste sentido haveria então, um elo que intermediasse o estímulo e a resposta. Esse elo intermediário pode ser considerado como um elo intermediário de segunda ordem, onde cria uma relação entre o estímulo e a resposta.

Assim, Vygotsky desenvolve o conceito mais básico da teoria da atividade que é a ação de um sujeito mediada por artefatos e destinada a um objeto. Ela considera todo um sistema de trabalho/atividade (incluindo equipes, organizações, etc.) além de apenas um ator ou usuário. Entra em consideração com o ambiente, a história da pessoa, a cultura, o papel do artefato, as motivações e a complexidade da atividade da vida real. Um dos pontos fortes da teoria da atividade é que ela faz a ponte entre o sujeito individual e a realidade social, ou seja, ela estuda ambos através da atividade de mediação. A unidade de análise na teoria da atividade é o conceito de atividade humana culturalmente mediada, coletiva e orientada a objetos, ou sistema de atividade. Esse sistema inclui o objeto (ou objetivo), assunto, artefatos mediadores (sinais e ferramentas), regras, comunidade e divisão do trabalho (LEONTIEV, 1983). 
Segundo Bannon (1997), a interação entre o homem e os objetos se dá em uma realidade objetiva que determina a natureza dos fenômenos subjetivos, ou seja, os constituintes dessa realidade não possuem propriedades consideradas objetivas apenas pelas ciências naturais, mas também definidas social e culturalmente. $\mathrm{O}$ autor destaca ainda que, a mediação por ferramentas é um dos princípios da teoria, uma vez que ela molda a maneira como os seres humanos interagem com a realidade.

As ferramentas de mediação podem ser entendidas como pertencentes a dois tipos: as ferramentas materiais (lápis, martelo etc.) e as ferramentas psicológicas como signos e símbolos, sendo a linguagem a ferramenta psicológica mais poderosa com a qual as pessoas se comunicam, interagem, experimentam e constroem a sua realidade.

No decorrer da história da humanidade, os homens construíram infindáveis objetos para satisfazerem suas necessidades. Ao fazê-lo, produziram não só objetos, mas também novas necessidades e, com isso, novas atividades. Superaram as necessidades biológicas e construíram a humanidade, reino das necessidades espirituais, humano-genéricas. Analisar, portanto, as necessidades humanas, requer compreendê-las em sua construção histórica. Tais atividades diferem por diversas razões: vias de realização, tensão emocional, formas etc., mas o fundamental que distingue uma atividade de outra é seu objeto, isto é, "o objeto da atividade é seu motivo real" (LEONTIEV, 1983).

Necessidade, objeto e motivo são componentes estruturais da atividade. Além desses, a atividade não pode existir senão pelas ações, constituindo-se pelo conjunto de ações subordinadas a objetivos parciais advindos do objetivo geral. Assim como a atividade relaciona-se com o motivo, as ações relacionam-se com os objetivos.

Leontiev (1983) mostra que as ações apresentam, além do aspecto intencional, o aspecto operacional, isto é, a forma como se realizam as operações. Cada ação inclui diferentes operações que dependem das condições de execução da ação. Neste sentido, pode-se apreender que as operações se referem aos inúmeros procedimentos que o sujeito realizará para alcançar seu objetivo, ou seja, a operação é a tecnificação da ação e, em geral, realiza-se automaticamente.

Os componentes da atividade podem adquirir diferentes funções, pois estão em constante processo de transformação. Uma atividade pode tornar-se ação quando perde seu motivo originário, ou uma ação transformar-se em atividade na medida em que ganha um motivo próprio, ou ainda uma ação pode tornarse operação e vice-versa. Assim, pesquisar a atividade requer a análise de sua estrutura e das relações entre seus componentes, requer descobrir qual é o motivo da atividade.

Para a psicologia histórico-cultural, a necessidade é o que dirige e regula a atividade concreta do sujeito em um meio objetal. Uma necessidade não é capaz de provocar nenhuma atividade de modo definido. Somente quando um objeto corresponde à necessidade, esta pode orientar e regular a atividade. Uma necessidade só pode ser satisfeita quando encontra um objeto, ou seja, um motivo. O motivo é o que impulsiona uma atividade, pois articula uma necessidade a um objeto (LEONTIEV, 1978).

Para Leontiev (1983), tanto as atividades externas quanto as internas apresentam a mesma estrutura geral. A atividade interna é constituída a partir da atividade prática sensorial externa, ou seja, a forma 
primária fundamental da atividade é a forma externa, sensório prática, não apenas individual, mas fundamentalmente social. A transformação da atividade externa em interna acontece por meio do processo de internalização. A passagem do externo para o interno dá lugar a uma forma específica de reflexo psíquico da realidade: a consciência. Leontiev define a consciência como conhecimento partilhado, como uma realização social. A consciência individual só pode existir a partir de uma consciência social que tem na linguagem seu substrato real.

Para Asbahr (2005), a consciência é o produto subjetivo da atividade dos homens com os outros homens e com os objetos; assim, a atividade constitui a substância da consciência, e para estudá-la é necessário investigar as particularidades da atividade, ou seja, "consiste, portanto, em encontrar a estrutura da atividade humana engendrada por condições históricas concretas, depois, a partir desta estrutura, pôr em evidência as particularidades psicológicas da estrutura da consciência dos homens". Asbahr (2005) entende que:

A consciência não se reduz a um mundo interno, isolado; ao contrário, se está intimamente vinculada à atividade, só pode ser expressão das relações do indivíduo com os outros homens e com o mundo circundante, sendo social por natureza. Mas a passagem do mundo social ao mundo interno, psíquico, não se dá de maneira direta, pois o mundo psíquico não é cópia do mundo social. No trânsito da consciência social para a consciência individual, a linguagem e a atividade coletiva laboral têm papel fundamental. Sendo o trabalho atividade socialmente organizada, a linguagem torna-se necessidade e condição para o desenvolvimento social e individual dos homens. Pela linguagem os homens compartilham representações, conceitos, técnicas, e os transmitem às próximas gerações. 0 homem apropria-se das significações sociais expressas pela linguagem e confere-lhes um sentido próprio, um sentido pessoal vinculado diretamente à sua vida concreta, às suas necessidades, motivos e sentimentos. A relação entre a significação social, o sentido pessoal e o conteúdo sensível, emocional, é o principal componente da estrutura interna da consciência.

Os autores soviéticos, apoiando-se nas análises feitas por Marx sobre o trabalho humano, mostram que, na sociedade capitalista, o conteúdo das ações dos trabalhadores e o motivo pelo qual agem são contraditórios, havendo uma ruptura entre significados e sentidos. Essa questão é fundamental na pesquisa que se utiliza dessa abordagem como referencial teórico metodológico (DUARTE, 2003).

\section{METODOLOGIA}

O estudo foi realizado na padaria artesanal 'Mãos de Fibra' da Violeira, localizada na zona rural do município de Viçosa/MG, que pertence à microrregião de Viçosa/MG e à mesorregião da Zona da Mata mineira. $\mathrm{O}$ estudo enquadra-se no tipo descritivo exploratório, de abordagem qualitativa, que fez uso, tanto na pesquisa documental como na entrevista em profundidade, da observação direta e de relatos verbais. As entrevistas com os membros do grupo tiveram como objetivo conhecer a percepção dos sujeitos acerca de sua realidade, bem como detectar quais as estratégias de ação estão sendo trabalhadas a fim de alcançar os objetivos que eles consideram importantes para o andamento das atividades do grupo e consequente obtenção de resultados positivos, tanto para eles, quanto para suas famílias, bem como toda a sociedade viçosense. 
As visitas à padaria aconteceram entre os meses de agosto e novembro de 2015, e foram acompanhadas todas as atividades desenvolvidas pelos sujeitos referentes à padaria artesanal. Tais atividades se constituíram da aquisição de insumos, produção, embalagem e comercialização dos produtos, que, no caso, correspondem aos pães integrais, comuns, de abóbora, de mandioca e de cebola.

O instrumento de análise dessas atividades foi a Teoria da Atividade, que tem como pressuposto a ideia de que a atividade coletiva é orientada para o objeto e mediada por elementos que fazem a ponte entre os sujeitos individuais e a estrutura social. As atividades humanas, mesmo que realizadas individualmente, estão relacionadas com práticas estabelecidas, histórica e coletivamente na sociedade, respondendo sempre às necessidades e sendo direcionadas por motivações específicas (LEONTIEV, 1981; ENGESTROM et al., 1999). Tal teoria tem como princípios básicos a unidade entre consciência e atividade, orientação a objetos, internalização-externalização, mediação por instrumentos, estrutura hierárquica da atividade e desenvolvimento contínuo.

A teoria da atividade é particularmente útil como uma lente em metodologias de pesquisa qualitativa (por exemplo, etnografia, estudo de caso). A teoria da atividade fornece um método de compreensão e análise de um fenômeno, encontrando padrões e fazendo inferências através de interações, descrevendo fenômenos e apresentando fenômenos através de uma linguagem e retórica embutida. Uma atividade em particular é uma interação propositada ou dirigida a objetivos de um sujeito com um objeto através do uso de ferramentas. Essas ferramentas são formas exteriorizadas de processos mentais que se manifestam em construções, sejam elas físicas ou psicológicas. A teoria da atividade reconhece a internalização e a externalização de processos cognitivos envolvidos na utilização de ferramentas, bem como a transformação ou desenvolvimento que resulta da interação.

Procurou-se, no presente estudo, observar como cada um desses princípios se fez presente durante a realização das diferentes atividades. Baseando-se em Lave (1991), no estudo da prática cotidiana, as pessoas foram acompanhadas em seu trabalho, utilizando-se da observação direta para conhecer a arena onde se desenvolvem as atividades do grupo, bem como para definir e descrever os diferentes cenários relativos ao funcionamento da padaria artesanal em questão. Os dados coletados foram analisados a partir da sistematização das observações e do conteúdo das falas dos sujeitos envolvidos no estudo durante o trabalho de campo.

\section{RESULTADOS E DISCUSSÃO}

\section{Construindo um quadro: definição das arenas e descrição dos cenários}

As comunidades rurais do município de Viçosa, como em outras cidades mineiras, apresentam uma estrutura e uma forma de organização similares, em que as pessoas residentes nesses locais são, em sua maioria, agricultores familiares. A comunidade estudada também possui um modo de vida semelhante, cuja mão de obra masculina é, em sua maioria, absorvida na agricultura. Já a feminina e jovem, nem tanto, sendo que as mulheres atuam mais nos afazeres domésticos, embora existam mulheres exercendo atividades remuneradas, como empregadas domésticas e faxineiras. Por outro lado, os jovens, quando não dispõem de 
afazeres que condizem com suas aspirações e conhecimento, podem permanecer em seu local de residência sem ter o que fazer ou deixam as comunidades rurais em busca de melhores oportunidades na zona urbana (BRUMER, 2004).

Nesse contexto de pouca valorização do trabalho feminino e jovem das comunidades rurais no município de Viçosa, sobressaiu-se uma mulher que exercia a atividade de empregada doméstica e nas horas vagas, geralmente à noite, produzia pães caseiros para comercialização. Com o passar do tempo, ela se viu compelida a aumentar sua produção, buscando ajuda de outras mulheres e jovens e, assim, surgiu a padaria comunitária da Violeira, que foi crescendo e se firmando na região.

As pessoas que atuavam e que atuam nesse empreendimento, fazem parte do grupo de amizades da idealizadora do empreendimento, sendo então convidadas por ela a fazerem parte do projeto. Dessa forma, as pessoas foram se agregando ao grupo, que cresceu, dando origem à padaria artesanal 'Mãos de Fibra', cujo nome busca resgatar a identidade cultural das agricultoras: o trabalho com as mãos e a força de vontade para mudar a difícil realidade em que tradicionalmente viveram. Daí a referência à fibra.

A forma pela qual esse grupo foi organizado para a fundação de um empreendimento comum nos remete à Gaiger (1999), que traz para a discussão acadêmica as práticas solidárias exercidas por diferentes grupos. Gaiger (1999) se refere ao termo "Economia Solidária" para designar um fenômeno relacionado ao crescimento e à expansão das iniciativas populares de geração de trabalho e renda, baseadas na livre associação entre trabalhadores e nos princípios de autogestão e cooperação, conforme evidenciado no presente estudo. Gaiger (1999) afirma que os empreendimentos realizados dentro dessa perspectiva envolvem as mais diversas categorias sociais e comportam distintas formas de organização, sendo que tais empreendimentos solidários aparecem com grande força em grupos familiares e comunitários.

A padaria artesanal 'Mãos de Fibra' foi criada em 2004, na comunidade da Violeira, zona rural do município de Viçosa/MG. Atualmente a referida padaria possui sede própria, localizada também na comunidade da Violeira. Anteriormente as atividades da padaria eram realizadas em um sítio pertence a uma das integrantes da padaria. Ao longo das visitas realizadas à padaria, foi possível observar que os membros atuais do empreendimento, devido à sua cumplicidade, organização e determinação, realizam as atividades inerentes ao processo produtivo de forma organizada, sistematizada e cooperativa. Com as visitas, foi possível também identificar tanto as arenas quanto os cenários relativos à produção de pães. Os cenários dizem respeito aos sujeitos agindo nas arenas, ou seja, nos locais onde ocorre a produção dos pães, quais sejam: as dependências internas da agroindústria familiar em questão.

As atividades exercidas pelos sujeitos nessa arena configuram todo o trabalho de produção, embalagem e comercialização dos produtos, sendo que, no último caso, diz respeito à entrega das encomendas aos clientes. Desse modo, os cenários envolvidos nessa última atividade referem-se ao local onde os clientes recebem os pães, juntamente com a ação dos mesmos e dos membros do grupo no momento da entrega dos produtos. 


\section{Atividades cotidianas da padaria artesanal 'Mãos de Fibra'}

As atividades de produção são realizadas por todos os membros do grupo, já as atividades de compra de insumos e confecção das etiquetas e das listas de clientes são desenvolvidas por membros específicos devido à sua maior habilidade e pelo poder dado a eles pelos membros do grupo para que pudessem realizálas. Tal fato pode ser comprovado no trecho abaixo, destacando-se que determinadas atividades são realizadas por pessoas específicas, conforme suas habilidades. A estrutura básica das atividades realizadas pelo grupo é apresentada na figura 1.

Daniel e Fernando, responsáveis por servir os participantes do seminário do qual tinham sido contratados. Essa atividade é realizada pelos dois e não por outros membros do grupo, uma vez que eles já possuem experiência nesse tipo de atividade, ressalta-se ainda a grande habilidade do Fernando em servir, visto que ele realiza atividades de garçom.

Fornos, vasilhames, móveis e utensílios, experiências, técnicas, habilidades. (mediação por instrumentos)

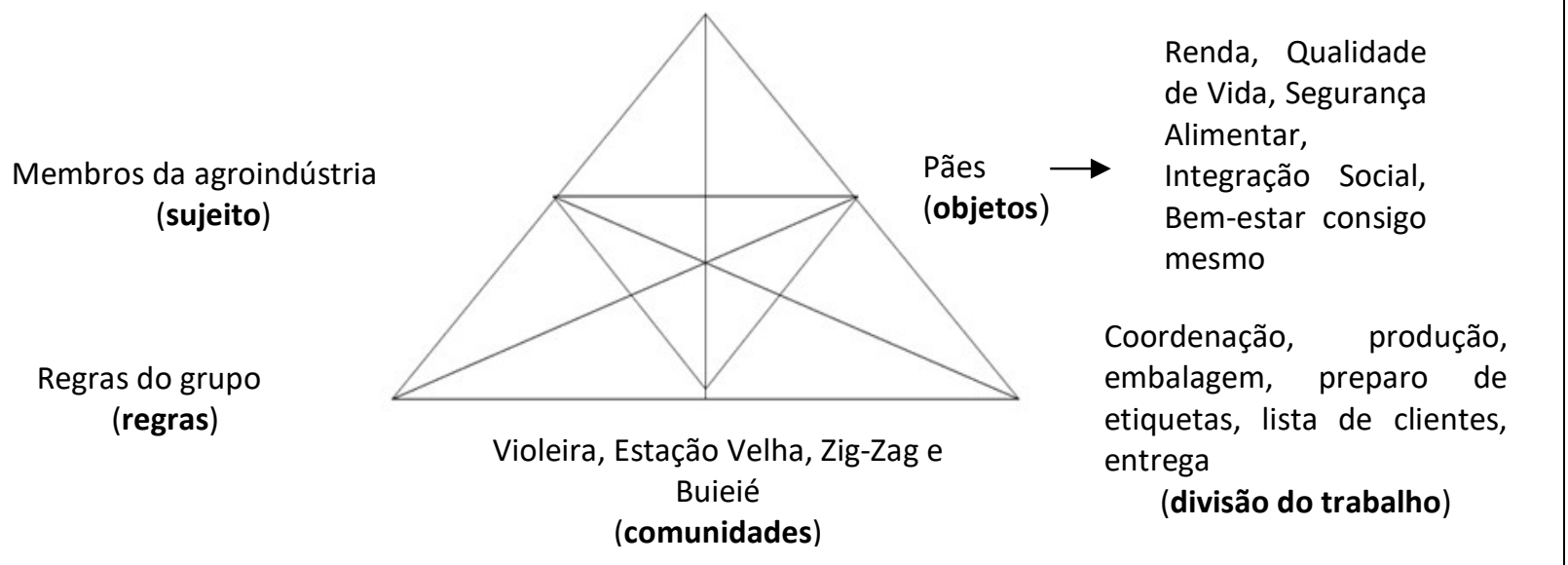

Figura 1: Estrutura básica das atividades realizadas na padaria artesanal 'Mãos de Fibra' da Violeira, Viçosa/MG.

Essa estrutura, segundo Boing (2003), contempla as regras existentes dentro da padaria artesanal e sua forma de divisão de trabalho. Ambas, em conjunto, formam o contexto em que estão envolvidas as atividades relativas à produção de pães. Os resultados das atividades ocorrem com a utilização de instrumentos, sob a ótica do contexto envolvido, gerando as saídas do processo.

Nessa estrutura, os membros da padaria artesanal representam os indivíduos ou subgrupos, cuja forma de agir é tomada como ponto de vista de análise. Os pães são o resultado final da padaria artesanal e fornecem meios para o alcance da qualidade de vida, que está associada às necessidades e motivos sobre os quais as atividades estão baseadas. Fornos, vasilhames, móveis, utensílios, bem como experiências, técnicas, habilidades dizem respeito aos esforços feitos pelos sujeitos na busca do resultado desejado; sendo que, para isso, utilizam de elementos que os ajudam a alcançar seus objetivos.

As comunidades da Violeira, Estação Velha, Zig-Zag e Buieié representam indivíduos/comunidades que possuem interesses comuns e compartilham do mesmo objeto (necessidade e razão da atividade), ou seja, a produção de pães, como forma de alcance de renda, segurança alimentar e integração social. A divisão do trabalho em etapas de produção, embalagem, preparo de etiquetas e lista de clientes, entrega e 
coordenação das atividades e do grupo referem-se à divisão horizontal de tarefas entre os membros da padaria artesanal.

As regras do grupo referem-se aos hábitos, normas e convenções, que restringem ações e interações no interior do sistema de atividades. Nesse caso, observou-se que as regras existentes se centram principalmente no princípio da cooperação, em que cada membro do grupo deve ajudar o outro na consecução da atividade que ele está realizando, para que ela seja realizada o mais rápido possível, sem sobrecarregar os sujeitos. Porém, há de se ressaltar, que mesmo havendo essa "cooperação" existe uma hierarquia, ou seja, certos membros do grupo detém a função de realizar certo tipo de atividade e os demais que atuam nela, exercem a função de ajudantes.

Quando algum dos membros falta ao trabalho, observou-se um empenho mais acentuado dos demais. Isso acontece para que a qualidade, a quantidade e o tempo de entrega dos pães não sejam comprometidos, revelando a existência de uma organização do processo produtivo, em que cada qual sabe o lugar que ocupa e quais atitudes devem ser tomadas para que o processo aconteça conforme o esperado.

Outra regra importante observada diz respeito às práticas higiênicas, destacando-se o uso do jaleco, da touca e, principalmente, a lavagem constante das mãos, além da higiene dos equipamentos, móveis e utensílios. As regras relativas à produção são também seguidas à risca, como a conferência da qualidade das matérias-primas antes da produção de cada massa, a fidedignidade aos pesos e medidas, a concentração por parte daqueles que estão atuando no preparo da massa, a produção de pães uniformes com vistas à qualidade do produto e o cumprimento dos prazos de entrega, que ocorrem sempre ao final da produção. Todas essas regras são pré-estabelecidas pelo grupo com o intuito de obter os resultados esperados, que seriam o cumprimento de todos os pedidos realizados pelos clientes, com qualidade dos produtos e no tempo pré-estabelecido.

Dessa forma tem-se que, conforme salienta Engestrom et al. (1999), um sistema de atividades sempre leva a algum resultado, que, no presente estudo, diz respeito à produção de pães com qualidade. Percebe-se, assim, que o sistema de atividades elencado anteriormente corrobora as ideias de Komosinski (2000) ao destacar que a ação mediada por instrumentos na transformação do objeto e realizada pelos sujeitos ocorre dentro de uma comunidade ou grupo, seja ele qual for, sendo não direta a relação sujeito/comunidade, mas sim mediada por regras que podem ser tanto explícitas (leis) quanto implícitas (convenções e relações sociais). No estudo em questão, as regras relacionam-se aos modos de ser dos sujeitos, suas bagagens de conhecimentos e formas de ver a vida, sua relação com as comunidades às quais pertencem e com os sujeitos com os quais interagem, durante todo o processo de produção e comercialização dos produtos.

Desse modo, o desempenho dos sujeitos não depende, portanto, apenas das suas habilidades cognitivas individuais, mas também das suas relações com as comunidades e com os outros membros do grupo. Com isso, percebe-se também o surgimento de uma organização explícita e implícita do grupo, sendo que a organização explícita se refere aos cargos oficiais ocupados pelos membros do grupo, que no caso se relacionam aos cargos da coordenadora Maria e do tesoureiro Daniel. Essa organização não se deu de forma 
aleatória, mas devido às habilidades dos sujeitos elencados para os seguintes cargos e pelo poder delegado a eles pelos outros membros do grupo, para que exercessem essas funções específicas, além das de produção dos pães, embalagem e entrega comum a todos. Esse fato é evidenciado nas falas da coordenadora da padaria artesanal.

Eu sou coordenadora porque só eu que sabia fazer o pão integral, eu já fazia em casa, fazia 25 pães por semana, então quando surgiu o projeto da padaria só foi pra frente porque eu assumi a responsabilidade de coordenar e ensinar o grupo. Agora todo mundo já trabalha sozinho, mas por uns dois anos eu é que coordenava tudo, os demais participantes não faziam nada sozinhos porque tinham medo. Hoje já fazem, quando eu falto, eles assumem tudo; agora a ideia da lista de clientes, as etiquetas, a ideia de colocar os pães para esfriar em cima da grade foi tudo eu que passei para o grupo, porque já era coisa que eu fazia sozinha;

O pão integral e o branco só eu sabia fazer, agora os bolos, pães de batata, mandioca, moranga, cebola é ideia de todo mundo, a gente vê o que fica melhor para produzir, mais barato;

Sempre somos nós que fazemos os orçamentos (Daniel e Maria). A gente aprendeu a fazer sozinho mesmo, porque teve uma época que o pessoal da Universidade que ia ensinar a gente direitinho, só que aí demorou e a gente viu que a necessidade era grande, então a gente mesmo fez, pesquisamos direitinho, a Vera da EMATER também nos ajudou, disse que o suco era $200 \mathrm{ml}$ por pessoa e assim a gente fez. Já são muitos anos fazendo isso, então já sabemos como fazer.

A organização implícita refere-se aos "cargos" criados pelo perfil de cada membro, caso do cargo de produtora de embalagens e etiquetas, exercido pela Júlia; entregador, exercido, principalmente, pelo Daniel, Fernando e José; operadora de fornalhas, exercida pela Maria, Cláudia e Vânia; lavadora de louças, atividade atribuída, principalmente à Amélia; e o cargo de embaladora e organizadora das entregas, exercido principalmente pela Antônia. Conforme relatado por um membro do grupo: "Antoninha faz falta de manhã aqui na padaria, mas ela faz falta mesmo é à tarde porque é ela quem sabe organizar melhor a saída dos pães, arrumar tudo e programar a entrega".

Essa divisão de trabalho em cargos não explícitos que ocorre no cotidiano do grupo é fruto de capacidades já desenvolvidas ao longo da vida dos sujeitos ou adquiridas nas práticas cotidianas da padaria artesanal e exercidas, devido a ações conscientes, em busca da melhoria da produção, delegando, assim, alguma função específica àqueles que apresentam maior afinidade com alguma atividade. Isso mostra que cada sujeito interage com suas atribuições de forma diferenciada, destacando-se aqueles que mais têm experiência e aptidão, em detrimento de outros que não fazem parte das aptidões natas ou adquiridas.

\section{Descrição das atividades cotidianas}

A atividade de compra de insumos é realizada por dois membros da padaria artesanal, que exercem as funções de coordenadora e tesoureiro. A definição da função de coordenadora se deu pelo fato de a mesma ser a mais experiente da padaria, uma vez que ela já produzia pães em sua residência antes de o grupo se formar. Desse modo, ela já possuía as técnicas que são usadas hoje pelos demais membros do grupo, tais como: a forma de produção, de resfriamento dos pães, de embalagens etc. Considera-se relevante destacar que foi a referida coordenadora que deu início ao projeto, recrutando os demais membros, transmitindo os conhecimentos e coordenando o grupo. 
O exercício da função permanece até os dias atuais, devido ao fato de não haver, por parte do grupo, interesse em mudanças, conforme relata a coordenadora: "Tudo que eu sabia eu ia passando para o grupo, fui ensinando o Daniel e hoje ele me ajuda. Então, assim, até hoje eu sou a coordenadora e ninguém nunca pediu para trocar não, não sei agora com o grupo mais formado se vai mudar".

A função de tesoureiro é creditada ao Daniel por motivos semelhantes aos da coordenadora, uma vez que ele atua na padaria artesanal desde a sua implantação, tendo obtido dos demais membros do grupo a aprovação para exercê-la. Todas as posições dos sujeitos nas etapas de produção são evidenciadas na Figura 2.

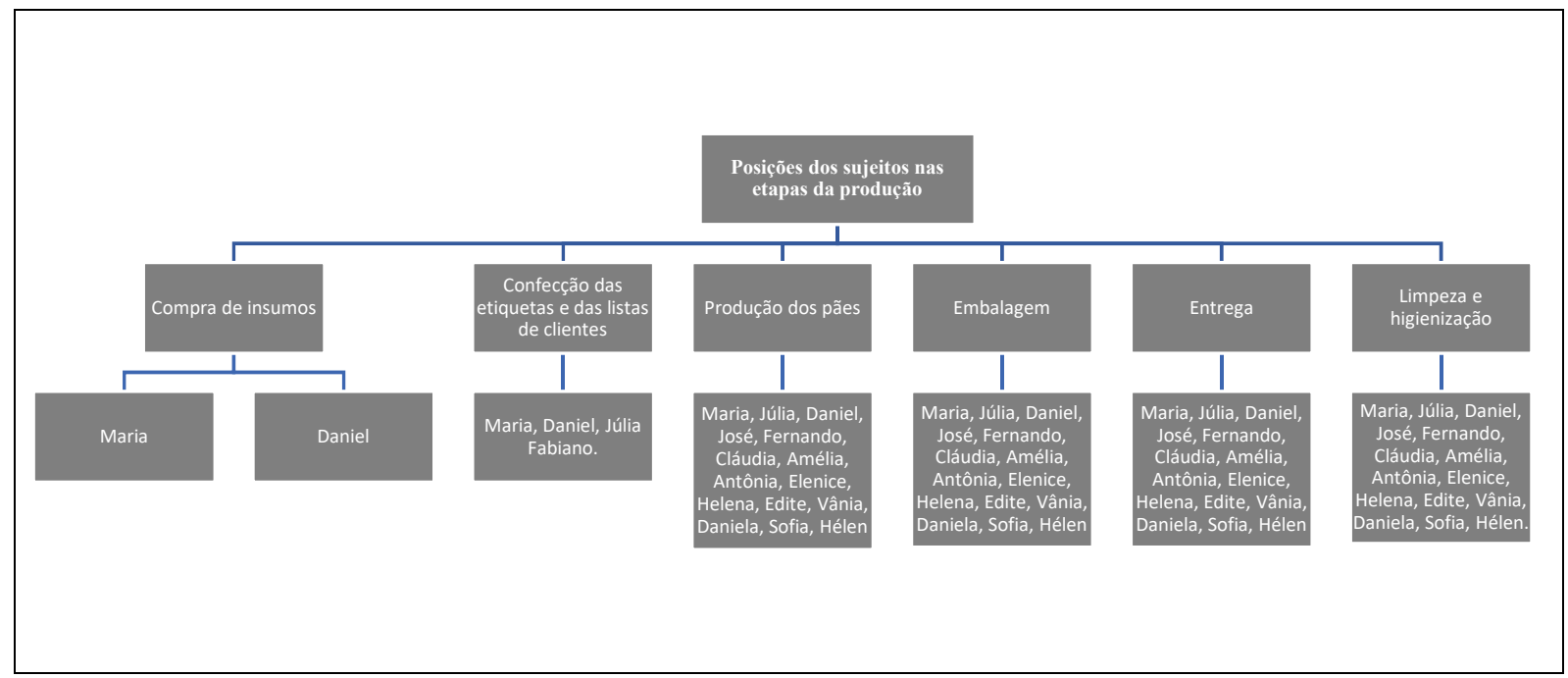

Figura 2: Organograma das posições dos sujeitos nas etapas de produção de pães.

Nas etapas de produção, tem-se a compra de insumos, que é feita com a renda proveniente da comercialização dos pães e da prestação de serviços em coffee breaks na cidade. As compras são feitas de acordo com as necessidades postas pelas demandas apresentadas, uma vez que ainda não possuem caixa para aquisição antecipada. O dinheiro destinado a esse fim é proveniente do pagamento dos clientes, que ocorre de forma estratificada, sem dia certo. Isso faz com que a padaria artesanal não possua um montante grande de dinheiro que seja suficiente para comprar grandes volumes de insumos.

O que se denomina atividade de limpeza e higienização é realizada em todos os dias de produção e fica a cargo da pessoa que chega primeiro ao local, embora se tenha percebido que tais atividades são exercidas, com maior regularidade, por determinadas pessoas. No que tange à confecção de etiquetas utilizadas nas embalagens e lista de clientes, percebeu-se que tal atividade é exercida, com maior regularidade, por três membros do grupo. E embora não se tenha determinado essa divisão, ela se deu em função de maior identificação dos sujeitos com a referida atividade.

A dinâmica da atividade de produção é realizada da seguinte maneira: enquanto alguns membros do grupo separam os ingredientes e utensílios, outros atuam no aquecimento da água, na preparação das formas, no acendimento dos fornos, na preparação da bancada, onde a massa é modelada, no local onde ela descansará para que haja o crescimento até que ela seja levada ao forno. Os pães são levados ao forno por cerca de cinquenta minutos. Neste período, os membros do grupo se revezam na atividade de 
acompanhamento do processo de cozimento dos pães até que estejam assados. Enquanto os pães assam, o grupo que não está realizando nenhuma atividade, começa a preparar a segunda massa e, assim, sucessivamente, até que o número de pães encomendados e aqueles destinados aos membros do grupo estejam prontos.

Assim que toda a produção do dia está terminada, inicia-se a atividade de embalagem dos pães, geralmente realizada por três a quatro pessoas, independentemente de sua função na padaria. O restante do grupo atua nas demais atividades de limpeza do ambiente, lavagem dos vasilhames e utensílios e outra atividade que, por ventura, suja naquele momento. Após a embalagem, os pães são entregues aos clientes, sendo a entrega feita a pé, por alguns membros do grupo, aos clientes que residem próximos à padaria, como também de ônibus, quando os clientes residem na zona urbana. Essa atividade de entrega é feita pelos membros do grupo que mais conhecem os locais de residência dos clientes e que tenham tempo disponível após o encerramento das atividades de produção, embora a atividade de entrega na zona urbana seja realizada com maior frequência pelos três membros homens da padaria.

Como o cotidiano é marcado por improvisações, no dia a dia da padaria não poderia ser diferente, o grupo, se deparando com situações inesperadas com bastante frequência, busca solucioná-las por meio do trabalho cooperativo e do diálogo entre os membros. Percebeu-se também que a coordenadora do grupo geralmente assume a liderança na busca por soluções, conforme evidenciado no seu relato: "Eu não tenho costume de experimentar essa massa, foi Deus que me fez fazer isso, imagina se eu não experimento e os pães são entregues sem sal? Poderíamos perder muitos clientes com isso”; “[...] na hora de preparar a massa, cada um tem que ficar com um produto para que isso não aconteça de novo, um tem que lembrar o outro. Tem que prestar atenção".

Com base em todo o exposto, evidenciou-se, no decorrer das observações diretas, que o cotidiano dos membros da padaria 'Mãos de Fibra' constitui a execução de um conjunto de atividades às vezes desenvolvidas simultaneamente. A participação em diferentes atividades, segundo os defensores da Teoria da Atividade, é o principal fator na criação da consciência e formação da personalidade dos sujeitos.

Há que se ressaltar que, apesar de as atividades realizadas no cotidiano da padaria parecerem idênticas quando visualizadas superficialmente, possibilitam aos sujeitos espaço de construção de conhecimento, desenvolvimento de habilidades e de interação, não apenas com os equipamentos e insumos, necessários à atividade, mas com os demais sujeitos envolvidos no processo, com pessoas externas ao processo, com os meios de comunicação, que alteram o modo como concebem a vida e a maneira como se posicionam socialmente no mundo.

Há, ao longo do tempo, mudança inevitável do pensamento humano, suas expectativas e experiências, seus anseios e realizações, além do seu desenvolvimento psíquico e laboral, que no caso, pode ser o ganho de autonomia, de prática e confiança. Além desses fatores, o contexto no qual a atividade acontece também apresenta variações, como a ausência de um ou mais membros do grupo, a utilização de um instrumento em detrimento a outro, as condições climáticas, que fazem com que a produção se torne mais rápida ou demorada. 
Ao longo do acompanhamento das atividades, detectou-se a manifestação de princípios inerentes à teoria da atividade, dentre eles, a mediação por instrumentos, tanto concretos quanto abstratos (esquemas de ação), a orientação aos objetos, ou seja, a realização das atividades com o objetivo de alcançar a segurança alimentar e auferir renda, a construção de conhecimento, o desenvolvimento humano, o que tem, por conseguinte, relação com a percepção que eles têm de si mesmos e da qualidade de suas 'vidas'.

\section{CONCLUSÕES}

O estudo do cotidiano mostrou a possibilidade de destacar os 'ganhos' dos grupos dentro de seu universo cotidiano e pode contribuir para a construção e/ou defesa de inclusão de nossos indicadores para aqueles que avaliam a sobrevida de agroindústrias alimentares. Tal fato permitiu compreender a dinâmica existente no interior do grupo, revelando as estratégias de ação trabalhadas pelos sujeitos, com vistas ao alcance de seus objetivos. As estratégias que mais se destacaram foram aquelas relativas ao trabalho cooperativo e à troca de conhecimentos, gerando resultados consistentes no que tange à melhoria da alimentação, que se deu por meio da obtenção de renda que, na maioria das vezes, é revertida em alimentos como também pelo consumo de pão integral proveniente da produção da padaria artesanal.

A Teoria da Atividade foi muito eficiente no entendimento das ações dos seres humanos, considerados seres sociais e históricos, implicando na valorização dos aspectos culturais, em oposição aos biológicos, como origem do comportamento humano. Ou seja, tanto o grupo estudado quanto toda a espécie humana são, ao mesmo tempo, produto e produtora de si mesma, devido às interações que estabelecem com outros sujeitos, das atividades que realizam e daquilo que pensam e compartilham com aqueles que atuam nas atividades da padaria. Nesse contexto, as conceituações de atividade e seus princípios norteadores permitiram entender a complexidade das atividades quando percebidas em seu contexto espaço temporal e sociocultural.

\section{REFERÊNCIAS}

ASBAHR, F. S. F. A pesquisa sobre a atividade pedagógica: contribuições da teoria da atividade. Revista Brasileira de Educação, Rio de Janeiro, n.29, p.108-118, 2005.

BANNON, L. J.. A Pilgrims Progress: from cognitive science to cooperative design. Al and Society, n.4 , p.259-275, 1997.

BIFANO, A. C. S. Estudo da Prática Situada: uma contribuição metodológica para avaliação e concepção de produtos. Dissertação (Mestrado em Engenharia de Produção) - Universidade Federal de Minas Gerais, Belo Horizonte, 1999.

BIFANO, A. C. S.. Um Estudo Ergonômico sobre a 'Sistemática de Posicionamento' no Quadro de Concepção e Desenvolvimento de Produto. Tese (Doutorado em Engenharia de Produção) - Universidade de São Paulo, São Paulo, 2007.

BOING, H.. Bases Metodológicas para a Construção de Ferramentas Computacionais para Programas Educacionais de Caráter Social. Tese (Doutorado em Engenharia de
Produção) - Universidade Federal de Santa Catarina, Florianópolis, 2003.

BRUMER, A.. Gênero e Agricultura: a situação da mulher na agricultura do Rio Grande do Sul. Estudos Feministas, Florianópolis, v.12, n.1, p.205-227, 2004.

CERTEAU, M.. A Invenção do Cotidiano: Artes de Fazer. Petrópolis: Vozes, 2001.

DUARTE, N.. A teoria da atividade como uma abordagem para a pesquisa em educação. Perspectiva, Florianópolis, v.21, n.2, p.229-301, 2003.

ENGESTRÖM, Y.; MIETTINEN, R.; PUNAMKI, R. L. Perspectives on Activity Theory. Cambridge: Cambridge University Press, 1999.

GAIGER, L. I.. Significados e Tendências da Economia Solidária. In: CUT. Central Único dos Trabalhadores. Sindicalismo e Economia Solidária: reflexões sobre o projeto da CUT. São Paulo: CUT, 1999. 
GIL, A. H. C. F.. Geografia do Cotidiano: uma leitura da metodologia socio-interacionista de Erving Goffman. Ateliê Geográfico, Goiânia, v.2, n.4, p.102-118, 2008.

KOMOSINSKI, L. J.. Um novo significado para a educação tecnológica fundamentado na informática como artefato mediador da aprendizagem. Tese (Doutorado em Engenharia de Produção) - Universidade Federal de Santa Catarina, Florianópolis, 2000.

KOZULIN, A.. O conceito de atividade na psicologia soviética: Vygotsky, seus discípulos, seus críticos. In: DANIELS, H.. Uma introdução a Vygotsky. São Paulo: Loyola, 2002. p.111-137.

KUUTTI, K.. Activity Theory as a potential framework for human-computer interation research. Cambridge: MIT Press, 1996.

LAVE, J.. Cognition in Practice: Mind, Mathematics and Culture in Everyday Life. Cambridge: Cambridge University Press, 1991.

LEFEVBRE, H.. Critique de la Quotidienne II: Fondements d'une Sociologie de la Quotidienneté, Paris: 1991.
LEONTIEV, A. N.. "The problem of activity in psychology". In: ERTSCH, J. V.. The Concept of Activity in Soviet Psychology. New York: Armonk, 1983. p.37-71.

LEONTIEV, A.. Sobre o desenvolvimento histórico da consciência. In: LEONTIEV, A. N.. O desenvolvimento do psiquismo. Lisboa: Horizonte Universitário, 1978. p.89-142.

LIMA, F. P. A.. Fundamentos Teóricos da Metodologia e Prática de Análise Ergonômica do Trabalho (A.E.T.). Belo Horizonte: UFMG, 1996.

LIMA, S. A.. Participação Social no Cotidiano. 5 ed. São Paulo: Cortez, 1983.

MARASCHIN, C.; TITTONI, J.. Cotidiano e Configuração de Espaços de Aprendizagem. Educar, Curitiba, n.19, p.147-157, 2002.

MARX, K.. Manuscritos econômicos-filosóficos. In: FERNANDES, F.. Marx e Engels: história. São Paulo: Ática, 1989. p.147-181.

PENIN, S.. Cotidiano e Escola: A Obra em Construção. São Paulo: Cortez, 1989. 